УДК 130.2

10.17213/2075-2067-2020-4-173-179

\title{
СОЦИОКУЛЬТУРНЫЕ ОСНОВАНИЯ ЭСТЕТИЧЕСКОГО ВОСПИТАНИЯ ПЕДАГОГОВ ТВОРЧЕСКИХ СПЕЦИАЛЬНОСТЕЙ
}

\author{
() 2020 г. С. И. Самыгин*, Д. С. Загутин**, Н. А. Шилина *** \\ *Ростовский государственный экономический университет (РИНХ), \\ 2. Ростов-на-Дону, Россия \\ **Ростовский юридический институт МВД России, г. Ростов-на-Дону, Россия \\ ***Академия архитектуры и искусств Южного федерального университета, \\ 2. Ростов-на-Дону, Россия
}

Цель статьи - обоснование необходимости учитывать сочуиокультурные основания эстетического воспитания при формировании педагогов творческих специальностей.

Методологические основания исследования составляют общенаучные принципь объективности, системности и историчности, находящие свое применение в широком пространстве общественного и гуманитарного знания.

Результаты исследования. Эстетическое воспитание педагогов творческих специальностей представляет собой элемент освоения культуры, но подразумевает определенную специфику, связанную с особенностями будущей профессиональной деятельности. Эстетическое воспитание будущих педагогов подразумевает формирование эстетической культуры как интегральной части личности педагога. Освоение эстетической культуры педагогами творческих специальностей подразумевает не только знаниевую, но и практическую составляющую и базируется на нескольких выделенных принщипах. Социокультурные основания выступают в качестве необходимого фундамента эстетического воспитания.

Перспективу исследования составляет дальнейший анализ значения и роли социокультурных оснований в эстетическом воспитании педагогов творческих специальностей.

Ключевые слова: эстетика; эстетическая культура; эстетическое воспитание; культура; сочиокультурное наследие; педагог.

\section{SOCIO-CULTURAL FOUNDATIONS OF AESTHETIC EDUCATION OF TEACHERS OF CREATIVE SPECIALTIES}

(C) 2020 S. I. Samygin*, D. S. Zagutin**, N. A. Shilina***

*Rostov State University of Economics (RSUE), Rostov-on-Don, Russia **Rostov Law Institute of the Ministry of Internal Affairs of Russia, Rostov-on-Don, Russia ***Academy of Architecture and Fine Arts of Southern Federal University, Rostov-on-Don, Russia

The purpose of the article is to substantiate the necessity to take into account sociocultural bases of aesthetic education when forming teachers of creative specialties.

The methodological basis of the study is the general scientific principles of objectivity, consistency and historicity, which are applied in a wide space of social and humanitarian knowledge. 
The results of the research. Aesthetic education of teachers of creative specialties is an element of mastering culture, but it implies a certain specificity associated with the features of future professional activity. Aesthetic education of future teachers implies the formation of aesthetic culture as an integral part of a teacher's personality. Mastering aesthetic culture by teachers of creative specialities implies not only a knowledgeable but also a practical component and is based on several selected principles. Sociocultural foundations serve as a necessary foundation for aesthetic education.

The prospect of the study is to further analyze the meaning and role of socio-cultural foundations in the education of teachers of creative specialties.

Key words: aesthetics; aesthetic culture; aesthetic education; culture; sociocultural heritage; teacher.

Введение. Сущностью эстетического воспитания является формирование у будущих педагогов эстетической культуры.

Согласно энциклопедии «Культурология», «эстетическая культура - это способность и умение прочувствовать свою связанность с миром, содержательно пережить и человечески ценностно выразить полноту и многообразие этих отношений. При этом специфику эстетического отношения составляют прежде всего два момента, касающиеся как своеобразия содержания этих отношений, характера их развертывания, так и механизма их осуществления, определяющего саму их специфичность. Это, во-первых, целостность, комплексность, всеохватывающий характер данного отношения, которое не может быть реализовано в частичной форме, например, только рационально или только чувственно. И, во вторых, это отношение, где принципиальное и конституирующее значение имеет качество не только той стороны, что традиционно именуется объектом отношения, но и стороны субъективной» [1].

Последний абзац процитированного определения ясно указывает на необходимость в процессе подготовки будущих педагогов творческих специальностей не просто привития им некоторого объема знаний, связанного с освоением уже имеющегося эстетически значимого культурного наследия, но и формирования у них определенных навыков, позволяющих стать если не творцами, то сотворцами эстетических ценностей [2], способными передать соответствующие качества своим ученикам. Можно сказать, что речь идет о формировании творческой элиты, способной не просто воспроизводить, но и твор- чески обогащать национальную и мировую эстетическую культуру.

Однако стать достоянием мировой культуры то или иное произведение культуры может, лишь опираясь на определенное наследие, самоопределяясь по отношению к нему, потому выдающиеся произведения мировой культуры являются одновременно и высочайшими образцами национальных культур, выразившими их дух [3], и в то же время преодолевшими их национальную замкнутость.

Такие произведения наглядно демонстрируют наличие универсальных эстетических ценностей, что и делает возможным вести речь о мировой культуре и мировом художественном наследии или достоянии. Таким образом, эстетическое воспитание будущих педагогов творческих специальностей должно включать два основных момента: овладение знанием эстетической культуры, позволяющим стать не бездумным, но понимающим наблюдателем и созерцателем эстетических ценностей, и формирование соответствующих профессиональных умений, которые превращают знатока и толкователя в творца, способного передавать эти умения новым поколениям учащихся [4].

Социокультурные основания эстетической деятельности. Способность к деятельности - базовая характеристика человека. Эстетическая деятельность выступает лишь как одна из составляющих деятельности, однако она крайне важна, о чем свидетельствует раннее ее происхождение. Практически одновременно с формированием человека современного типа - Homo Sapiens - обнаруживаются и следы эстетической деятельности, первого архаического искусства, при этом не- 
которые его образцы, прежде всего так называемая пещерная живопись, демонстрируют нередко высокий уровень мастерства. Пещерная живопись, обнаруживаемая на достаточно обширной территории, чаще всего демонстрирует сходство изобразительных приемов, однако дальнейшее развитие человечества, его расселение по обширным территориям и формирование разнообразных жизненных укладов в разных исторических обстоятельствах приводило к формированию того, что мы сейчас можем назвать этническими или национальными особенностями, что выражалось и в выработке своеобразных стилей художественного творчества, различий в эстетическом восприятии действительности.

Уже первые древние цивилизации демонстрируют значительное разнообразие художественных стилей и разнообразие стоящей за этими стилями эстетики. Невозможно перепутать произведение минойского, шумерского и египетского искусства, будучи даже лишь поверхностно знакомым с культурами этих цивилизаций. Удивительное своеобразие демонстрирует эстетическая культура древнего Китая, оказавшая значительное влияние на эстетику живущих рядом народов.

Эстетика любого народа является специфическим выражением общего исторического опыта, его ценностей [5], находящих зримое воплощение в формах изобразительной деятельности, её приемах и функциях. Не секрет, что на протяжении большей части человеческой истории то, что мы сегодня называем искусством, не было самозаконной и самоценной деятельностью: от живописи и скульптуры Древнего Египта до христианского искусства изобразительная деятельность выполняла в основном религиозные функции. Для древних государств важной была и идеологическая функция искусства, объектом изобразительной деятельности выступали правители, их воинские подвиги, их взаимодействие с богами и мифическими героями и т.д. Творцы подобных эстетических артефактов, как правило, подчинялись определенным изобразительным канонам, «авторский стиль» практически неразличим в эстетическом наследии древних культур, хотя в некоторых случаях можно говорить и об обратном. И всё же «авторство» и произведение искусства как самовыражение автора в качестве нормы, а не исключения для искусства — это относительно недавнее историческое изобретение, связанное, как известно, с эпохой Возрождения, когда искусство, оставаясь по содержанию и функциям преимущественно религиозным, превратилось в пространство не воспроизводства канонических форм, а индивидуального творчества.

В дальнейшем секуляризация и индивидуализация искусства нарастали, и современное искусство, т.е. искусство эпохи Нового времени, знает школы и направления, но уже свободно от давления канона и идеологического контроля, какой бы инстанцией он не осуществлялся. Эстетическая деятельность приобрела самостоятельность по отношению к другим сферам деятельности в результате связанной с процессом модернизации дифференциации социокультурных сфер.

С другой стороны, сфера применения эстетического подхода к реальности расширяется, и говоря об эстетической деятельности, мы сегодня подразумеваем не только собственно искусство, но и такую прикладную по сути сферу профессиональной деятельности, как дизайн во всех его многочисленных аспектах. Благодаря развитию дизайна практически ни одна сфера деятельности современного человека не является свободной от эстетической составляющей. Но дизайн как профессиональная сфера возникал в тесной связи с логикой развития искусства на рубеже XIX-XX вв., предпосылки же дизайна мы можем обнаружить в далеком прошлом - в практике украшения предметов повседневного обихода, орудий труда и воинского снаряжения. Современный дизайн имеет тенденцию к выработке универсалистских стилей и техник, что объясняется глобализацией и универсализацией форм человеческого существования и деятельности - от развлечений до профессиональных занятий. Тем не менее, именно в условиях глобализма новую ценность приобретают локальные особенности, в том числе и локальные (национальные, этнические) художественные традиции и эстетические предпочтения.

Диалектика локального и универсального определяет динамику развития современной эстетической культуры, что должно найти свое воплощение и в выработке стратегий эстетического воспитания педагогов творчес- 
ких специальностей, для которых эстетическая культура является не отвлеченным понятием и абстрактной ценностью, а сферой профессиональной деятельности.

Социокультурные основания эстетического воспитания педагогов. Освоение эстетической культуры, являющееся сутью эстетического воспитания, представляет собой не только овладение новыми практическими навыками, но и расширение возможностей мировосприятия. Освоить и понять окружающий мир человек способен лишь на основе уже имеющегося опыта и тех навыков, которые привиты ему в ходе социализации и воспитания [6], в том числе и эстетического.

Эстетическое восприятие иерархично. Есть художественные артефакты, которые практически не требуют развитого эстетического восприятия. В современных условиях к сфере бытования таких артефактов можно отнести массовую культуру. Однако освоение и создание более сложных эстетических ценностей требует соответствующей подготовки. В условиях современного омассовления общества и культуры в специализированной подготовке и воспитании для своего восприятия нередко нуждаются не только образцы мировой культуры или иных национальных культур, но даже и эстетическое наследие культуры собственной.

Так, например, для большинства современных россиян недоступным для восприятия является не только так называемое «современное искусство» в узком смысле, подразумевающее знание специфических символических кодов для расшифровки эстетического смысла объекта, на первый взгляд, вовсе не имеющего никакой эстетической ценности, но и, например, православной иконописи.

Иконопись, с присущими ей своеобразными символическими кодами и подчиненностью иконописному канону, не воспринимается обыденным взглядом как эстетическая ценность, а в лучшем случае почитается как чисто религиозный объект [7], не имеющий к эстетике никакого отношения. Попытки же приблизить православную эстетическую культуру к обыденному восприятию порождают лишь «православный китч», своеобразное ответвление коммерческой массовой культуры. Таким образом, православная иконопись как часть российской социокультурной эстетической традиции остается во многом недоступной для полноценного восприятия зрителем и едва ли может стать сферой приложения творческих способностей современных художников.

То же самое касается и произведений народной культуры, часто подменяемых псевдонародными масскультурными суррогатами. Но не только восприятие иконописи и народного творчества затруднено для современной массовой аудитории. Это касается и наследия «высокой культуры» в самых разных её областях - от литературы до живописи. Таким образом, недоступным для широкой аудитории является не только ультрасовременное интеллектуальное искусство, но и то, что может быть отнесено к классическому наследию мировой и национальных культур.

В такой ситуации значение поддержки в проведении эстетического воспитания педагогов творческих специальностей возрастает, ведь их профессиональной обязанностью является не только хранение социокультурного наследия [8], но и приобщение к нему аудитории, и приращение этого наследия, творческое развитие уже существующих социокультурных традиций.

Учитывая специфику задач эстетического воспитания, оно должно соответствовать ряду принципов, которые можно обозначить как целостность, системность, историчность и продуктивность.

Принцип целостности подразумевает соединение полученных знаний и навыков в единое целое, вовлекающее личность целиком в процесс культурного воспроизводства и творческой деятельности.

Принципы целостности и системности удачно отражены в исследовании О. Суходольской-Кулешовой: «Эстетическая культура будущего учителя представляется как динамическая система знаний, ценностей, норм и моделей эстетического отношения к действительности, которые обеспечивают эстетизацию деятельности, поведения, среды обитания человека и раскрываются в процессе продуктивного освоения и трансляции эстетического опыта в профессионально-педагогической подготовке студента; интегрируют общечеловеческие, национальные культурно-эстетические ценности, проявляются в его личностном ценностно-эстетическом самоопределении и выступают устойчивым 
фактором сохранения равновесия между традициями и инновациями благодаря преемственности образования и передаче культурных ценностей от поколения к поколению, с одной стороны, и накоплению личностного инновационного потенциала с другой» [9].

Принцип историчности, на наш взгляд, подразумевает осознанную включенность личности будущего педагога в цепь преемственного развития эстетической культуры как национальной, так и мировой; включенность, позволяющую не только осознавать эстетическую ценность и символический смысл тех или иных культурных артефактов, понимать закономерности и тенденции их развития, но и творчески обогащать имеющееся социокультурное наследие.

Принцип продуктивности тесно связан с принципом историчности. Иными словами, социокультурные основания эстетической деятельности должны быть интериоризированы личностью будущего педагога, позволяя ему самому стать не только хранителем и толкователем, но и создателем эстетических ценностей, а также иметь навыки, позволяющие передавать эти качества будущим поколениям.

Подобные качества и навыки не могут формироваться «с чистого листа», но всегда имеют в качестве предпосылки социокультурное наследие, эстетическую традицию того или иного народа, творческое освоение которого становится необходимым элементом интеграции в культуру мировую.

Заключение. Освоение эстетической культуры является неотъемлемым элементом освоения культуры вообще, становления человеческой личности как культурного существа. Как отмечают многие современные авторы, «эстетическая культура - важнейшая составляющая духовного мира современной личности» [10].

Чем богаче и разнообразнее освоенный индивидом культурный опыт, тем шире его мировоззрение, тем более он способен творчески проявлять себя в самых разных областях деятельности, в том числе и деятельности, связанной с творческими специальностями в профессиональном смысле этого слова. Однако в сложных постсовременных обществах творческую или креативную составляющие имеют многие специальности, далеко выходящие за пределы сферы, обозначаемой как искусство, потому возрастает необходимость формирования такого качества, как креативность и способность к творческому мышлению, что ставит перед педагогами, особенно педагогами творческих специальностей, новые задачи.

Творческое освоение мирового культурного наследия, необходимое для педагогов, неизбежно должно начинаться с освоения собственного социокультурного наследия, и этот процесс является не только частью профессионального обучения, но также неотъемлемым элементом формирования личности.

\section{Литература}

1. Культурология. Энциклопедия. В 2-х томах. Том 2. / Главный редактор и автор проекта С.Я. Левит. - М.: РОССПЭН, 2007. $1184 \mathrm{c}$.

2. Kasyanov V.V., Davydova G.I., Shilina N.A., Aleshin S. V., Volkova D. V., Samygin S.I. Socio-cultural heritage of victory in the great patriotic war in the context of modern ethical and historical realities. Revista Inclusiones. 2019. - Vol. 6. — №S3-4. — Pp. 121-126.

3. Самыгин С.И., Касьянов В.В., Шилина Н.А. Граффити как явление художественных субкультурных практик в молодежной среде // Гуманитарные, социально-экономические и общественные науки. - 2018. №8. - C. 55-58.

4. Vaskov M., RezvanovA., Kasyanov V., Samygin S., Gafiatulina N., Zagutin D., Scherbakova $L$. Value orientations of russian youth in the system of managing the moral security of society // Вісник Національної академії керівних кадрів культури і мистецтв. - 2018. №2. - Рp. 134-140.

5. Загутин Д. С. Историческая память в культуре постмодерна // Гуманитарий Юга России. - 2020. - Т. 9. - №2. - С. 225-233.

6. Загирова Э. М., Гафиатулина Н.Х. Система ценностей молодежи и духовная безопасность современного российского общества // Гуманитарное знание и духовная безопасность. Сборник материалов IV Международной научно-практической конференции. - Грозный, 2017. - С. 241-246.

7. Белов М.Т., Гафиатулина Н.Х., Самыгин С.И. Управление религиозными ориентирами в сознании современной молодежи // 
Экономические проблемы России и региона. Ученые записки. Ростовский государственный экономический университет (РИНХ). Ростов-на-Дону, 2019. - С. 186-193.

8. Загутин Д. С., Гафиатулина Н.Х., Самылин С.И. Социальное здоровье российской студенческой молодежи в контексте реализации институциональных механизмов социальной поддержки // Гуманитарные, социально-экономические и общественные науки. - 2017. - №6-7. - С. 41-45.

9. Рахматуллина 3.Я., Фаткуллина 3.Я. Эстетическая культура личности и общества современное измерение // Вестник Башкирского университета. - 2008. - Т. 13. №4. - C. 1060-1061.

10. Суходольская-Кулешова О. Развитие эстетической культуры будущего учителя. Автореферат диссертации на соискание степени доктора пед. наук. - М.: 2006. [Электронный ресурс]. - Режим доступа: https://www.dissercat.com/content/razvitieesteticheskoi-kultury-budushchego-uchitelya.

\section{References}

1. Kul'turolorija. Jenciklopedija. V 2-h t. Tom 2 [Cultural studies. Encyclopedia. In 2 vols. Vol. 2]. / In S. Ja. Levit (ed.). - Moscow: ROSSPJeN, 2007. - 1184 p.

2. Kasyanov V.V., Davydova G.I., Shilina N.A., Aleshin S.V., Volkova D.V., Samygin S.I. Socio-cultural heritage of victory in the great patriotic war in the context of modern ethical and historical realities. Revista Inclusiones. 2019. - Vol. 6. - №S3-4. - Pp. 121-126.

3. Samygin S.I., Kas'janov V. V., Shilina N.A. Graffiti kak javlenie hudozhestvennyh subkul'turnyh praktik v molodezhnoj srede [Graffiti as a phenomenon of artistic subcultural practices in the youth environment] // Gumanitarnye, social'no-jekonomicheskie i obshhestvennye nauki [Humanities, socio-economic and social Sciences]. — 2018. — №8. - Pp. 55-58.

4. Vaskov M., Rezvanov A., Kasyanov V., Samygin S., Gafiatulina N., Zagutin D., Scherbakova L. Value orientations of russian youth in the system of managing the moral security of society // Visnik Nacional'noï akademiï kerivnih kadriv kul'turi i mistectv. - 2018. — №2. - Pp. 134-140.

Поступила в редакциию
5. Zagutin D.S. Istoricheskaja pamjat' $\mathrm{v}$ kul'ture postmoderna [Historical memory in postmodern culture] // Gumanitarij Juga Rossii [Humanities of the South of Russia]. - 2020. Vol. 9. - №2. - Pp. 225-233.

6. Zagirova Je. M., Gafiatulina N.H. Sistema cennostej molodezhi i duhovnaja bezopasnost' sovremennogo rossijskogo obshhestva [System of values of youth and spiritual security of modern Russian society] // Gumanitarnoe znanie i duhovnaja bezopasnost'. Sbornik materialov IV Mezhdunarodnoj nauchno-prakticheskoj konferencii [Humanitarian knowledge and spiritual security. Collection of materials of the IV International scientific and practical conference]. - Grozny, 2017. — Pp. 241-246.

7. Belov M.T., Gafiatulina N.H., Samygin S.I. Upravlenie religioznymi orientirami $\mathrm{v}$ soznanii sovremennoj molodezhi [Management of religious landmarks in the minds of modern youth] // Jekonomicheskie problemy Rossii i regiona. Uchenye zapiski. Rostovskij gosudarstvennyj jekonomicheskij universitet (RINH) [Economic problems of Russia and the region. Scientific notes. Rostov State University of Economics (RSUE)]. Rostov-on-Don, 2019. - Pp. 186-193.

8. Zagutin D.S., Gafiatulina N.H., Samygin S.I. Social'noe zdorov'e rossijskoj studencheskoj molodezhi $\mathrm{v}$ kontekste realizacii institucional'nyh mehanizmov social'noj podderzhki [Social health of Russian student youth in the context of implementation of institutional mechanisms of social support] // Gumanitarnye, social'no-jekonomicheskie i obshhestvennye nauki [Humanities, socio-economic and social Sciences]. - 2017. — №6-7. - Pp. 41-45.

9. Rahmatullina Z. Ja., Fatkullina Z. Ja. Jesteticheskaja kul'tura lichnosti i obshhestva sovremennoe izmerenie [Aesthetic culture of the individual and society modern dimension] // Vestnik Bashkirskogo universiteta [Bulletin of the Bashkir University]. — 2008. — Vol. 13. №4. - Pp. 1060-1061.

10. Suhodol'skaja-Kuleshova O. Razvitie jesteticheskoj kul'tury budushhego uchitelja. [Development of aesthetic culture of the future teacher. Ph. D. (Pedagogic) Thesis]. - Moscow: 2006. [Jelektronnyj resurs]. — URL: https://www.dissercat.com/content/razvitie-esteticheskoi-kultury-budushchego-uchitelya.

5 августа 2020 г. 


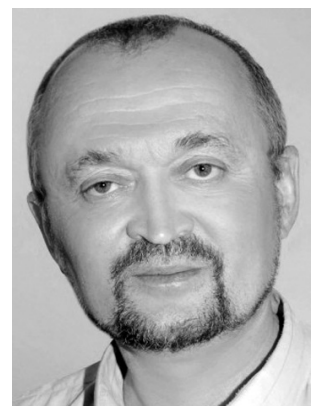

Самыгин Сергей Иванович - профессор, доктор социологических наук, профессор кафедры управления персоналом и социологии Ростовского государственного экономического университета (РИНХ).

Samygin Sergey Ivanovich - Professor, Doctor of Sociological Sciences, Professor, Department of Personnel Management and Sociology, Rostov State University of Economics (RSUE).

344002, г. Ростов-на-Дону, ул. Большая Садовая, 69

69 Bolshaya Sadovaya st., 344002, Rostov-on-Don, Russia

E-mail: darya.maksimovich@gmail.com

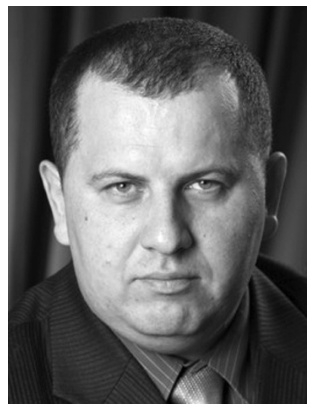

Загутин Дмитрий Сергеевич - доктор философских наук, кандидат технических наук, профессор Ростовского юридического института МВД России.

Zagutin Dmitry Sergeevich - Doctor of Philosophical Sciences, Candidate of Engineering Sciences, Professor of Department of Public Relations, Rostov Law Institute of the Ministry of Internal Affairs of Russia.

344015, г. Ростов-на-Дону, ул. Еременко, 83

83 Eremenko st., 344015, Rostov-on-Don, Russia

E-mail: rostov-zd@mail.ru

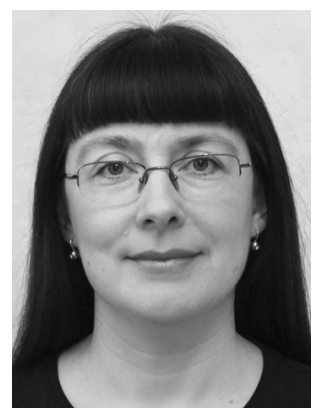

Шилина Наталья Анатольевна - кандидат социологических наук, доцент кафедры рисунка Академии архитектуры и искусств Южного федерального университета.

Shilina Natalya Anatolyevna - Candidate of Sociological Sciences, Associate Professor of the Drawing, Academy of Architecture and Fine Arts of Southern Federal University.

344082, г. Ростов-на-Дону, пр. Буденновский, 39

39 Budennovsky av., 344082, Rostov-on-Don, Russia

E-mail: rnd.natalia@mail.ru 